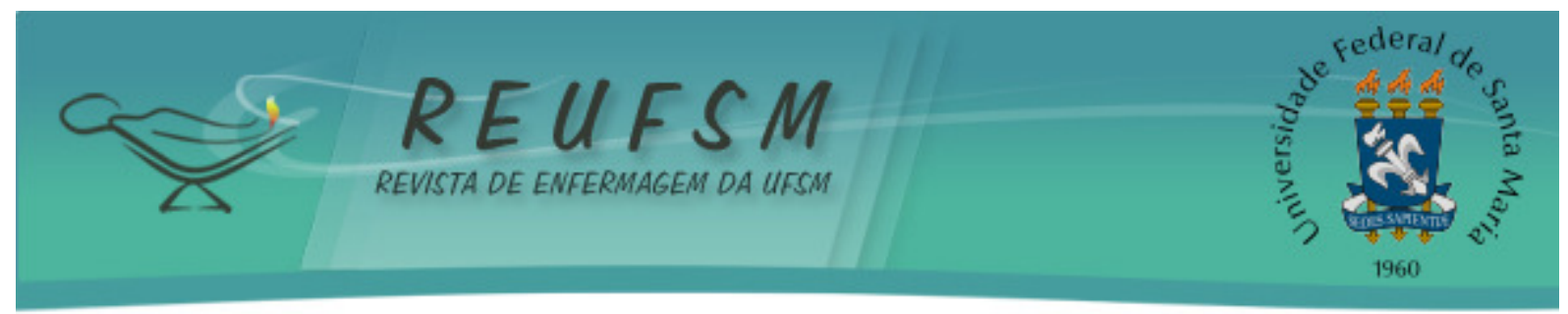

ARTIGO ORIGINAL

\title{
AS PLANTAS MEDICINAIS COMO POSSIBILIDADE DE CUIDADO PARA DISTÚRBIOS URINÁRIOS
}

MEDICINAL PLANTS AS A POSSIBILITY OF CARE FOR URINARY DISORDERS

LAS PLANTAS MEDICINALES COMO POSIBILIDAD DE CUIDADO PARA TRASTORNOS URINARIOS

Doi: $10.5902 / 2179769210377$

\author{
Andrieli Daiane Zdanski de Souza ${ }^{1}$ \\ Marjoriê da Costa Mendieta² \\ Teila Ceolin ${ }^{3}$ \\ Rita Maria Heck ${ }^{4}$
}

RESUMO: Objetivo: investigar as plantas medicinais indicadas para distúrbios urinários, por descendentes da zona rural de um município da região Sul do Rio Grande do Sul. Método: pesquisa qualitativa com nove participantes provenientes da zona rural do município de Capão do Leão, Rio Grande do Sul/RS. Os dados foram coletados entre julho e agosto de 2010, por meio de observação simples e entrevista semiestruturada, os quais foram comparados com estudos científicos. Resultados: sete plantas foram elencadas pelos participantes para distúrbios urinários (Bauhinia sp., Bidens alba, Equisetum hyemale, Fragaria vesca, Petroselium crispum, Phyllanthus sp., Plantago australis). Para todas foram encontrados estudos científicos que comprovaram os efeitos citados popularmente. Considerações Finais: conhecer e valorizar o saber popular sobre as plantas medicinais, assim como suas comprovações científicas, é importante para auxiliar os profissionais de saúde no seu processo de trabalho.

Descritores: Plantas medicinais; Sistema urinário; Infecções bacterianas; Enfermagem; Terapias complementares.

ABSTRACT: Aims: to investigate the medicinal plants recommended for urinary disorders, by descendents of the rural area of a town in the southern region of Rio Grande do Sul (RS). Method: qualitative research with nine participants from the rural area of the town Capão do Leão/RS. Data collection occurred between July and August of 2010 through simple observation and semi-structured interviews, which were compared with scientific studies. Results: seven plants for urinary disorders were listed by the participants (Bauhinia sp., Bidens alba, Equisetum hyemale, Fragaria vesca, Petroselium crispum, Phyllanthus sp., Plantago australis). Scientific studies about all of them were found, demonstrating their popularly known effects. Conclusions: It is important to know and value the popular knowledge about medicinal plants, as well as their scientific evidences in order to assist health professionals in their work.

Descriptors: Plants, medicinal; Urinary tract; Bacterial infections; Nursing; Complementary therapies.

\footnotetext{
1 Enfermeira. Mestre em Enfermagem pelo Programa de Pós-Graduação da Faculdade de Enfermagem da Universidade Federal de Pelotas (UFPel). Porto Alegre, RS, Brasil. E-mail: andriele_zdanski@hotmail.com

${ }^{2}$ Enfermeira. Mestranda do Programa de Pós-Graduação da Faculdade de Enfermagem da Universidade Federal de Pelotas (UFPel). Pelotas, RS, Brasil. E-mail: marjo.mendieta@ibest.com.br

3 Enfermeira. Doutoranda do Programa de Pós-Graduação da Faculdade de Enfermagem da Universidade Federal de Pelotas (UFPel). Professora Assistente da Faculdade de Enfermagem UFPel. Pelotas, RS, Brasil. Email: teila.ceolin@ig.com.br

${ }^{4}$ Enfermeira. Doutora em Enfermagem pela Universidade Federal de Santa Catarina. Professora Adjunta da Faculdade de Enfermagem da Universidade Federal de Pelotas. Pelotas, RS, Brasil. E-mail: heckpillon@yahoo.com.br
} 


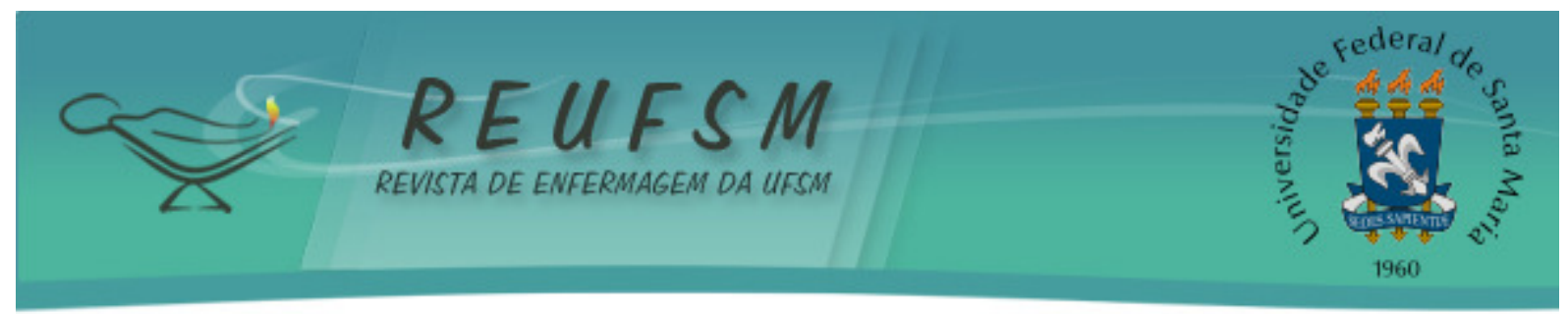

RESUMEN: Objetivo: investigar las plantas medicinales recomendadas para trastornos urinarios, por descendientes del área rural de un municipio de la región Sur del Rio Grande do Sul (RS-Brasil). Método: investigación cualitativa con nueve participantes originarios del área rural del municipio de Capão do Leão, RS. Los datos fueron recolectados entre julio y agosto de 2010, mediante observación simple y entrevistas semi-estructuradas, y fueron analizados y comparados con estudios científicos. Resultados: siete plantas fueron listadas por los participantes para trastornos urinarios (Bauhinia sp., Bidens alba, Equisetum hyemale, Fragaria vesca, Petroselium crispum, Phyllanthus sp., Plantago australis). Para todas ellas fueron encontrados estudios científicos que comprobaron los efectos citados popularmente. Consideraciones Finales: conocer y valorizar la sabiduría popular sobre las plantas medicinales, así como sus comprobaciones científicas, es importante para auxiliar a los profesionales de salud en su proceso de trabajo.

Descriptores: Plantas medicinales; Sistema urinario; Infecciones bacterianas; Enfermería; Terapias complementarias.

\section{INTRODUÇÃO}

A Organização Mundial de Saúde (OMS) considera as plantas medicinais um importante instrumento de assistência à saúde, a qual 70 a $90 \%$ da população nos países em desenvolvimento, faz uso dessas práticas. Diante desse dado, a OMS ressalta a necessidade de valorizar essa prática complementar no âmbito sanitário. ${ }^{1-2}$

Estudos $^{3-5}$ realizados em diversas regiões do Brasil revelam que a população faz uso de plantas medicinais no cuidado à saúde, o que demonstra a necessidade dos profissionais agregarem o conhecimento destas terapias ao seu ambiente laboral para que realizem o cuidado levando em consideração as práticas realizadas pela população.

Na perspectiva de ampliar essa opção terapêutica no Sistema Único de Saúde (SUS), em 2006 foi implementada a Política Nacional de Práticas Integrativas e Complementares (PNPIC), incentivando o uso das plantas medicinais, através da fitoterapia, homeopatia, acupuntura, entre outras práticas. ${ }^{6}$

Neste mesmo ano foi publicado o decreto $\mathrm{n}^{\circ} 5.813$, que aprovou a Política Nacional de Plantas Medicinais e Fitoterápicos (PNPMF). Esta política tem como objetivo garantir à população o acesso seguro e o uso racional de plantas medicinais e fitoterápicos, além de promover o uso sustentável da biodiversidade, o desenvolvimento da cadeia produtiva e da indústria nacional. ${ }^{7}$

As práticas complementares são aquelas que buscam complementar o tratamento alopático e não substituí-lo. Dentre as práticas consideradas complementares está o uso de plantas medicinais. ${ }^{8}$ Estas propõe à assistência a saúde do indivíduo de maneira integral, enfocando o cuidado à saúde e não a doença, buscando desenvolver ações de promoção da saúde. ${ }^{5}$

A partir da PNPIC e de outras políticas que discorrem sobre esse assunto, cada vez mais pesquisas científicas vêm sendo realizadas, baseadas no conhecimento popular, com o objetivo de testar e buscar efeitos de plantas que são utilizadas pela população ${ }^{3}$, dentre estas pesquisas, algumas estão voltadas para as infecções do trato urinário. ${ }^{9-10}$

Nessa perspectiva, os profissionais da atenção básica se deparam frequentemente com queixas relacionadas ao sistema urinário, ou seja, distúrbios que incluem infecções, padrões miccionais disfuncionais, urolitíase, câncer de trato urinário e desvios urinários. ${ }^{11}$

O enfermeiro, na sua prática diária, presencia várias práticas de cuidado que a população faz uso para o tratamento dos distúrbios urinários, dentre estas as plantas medicinais. Nesse contexto, quando o profissional possui conhecimento sobre esse assunto, a prática complementar das plantas medicinais pode ser incluída no cuidado realizado ao usuário. 


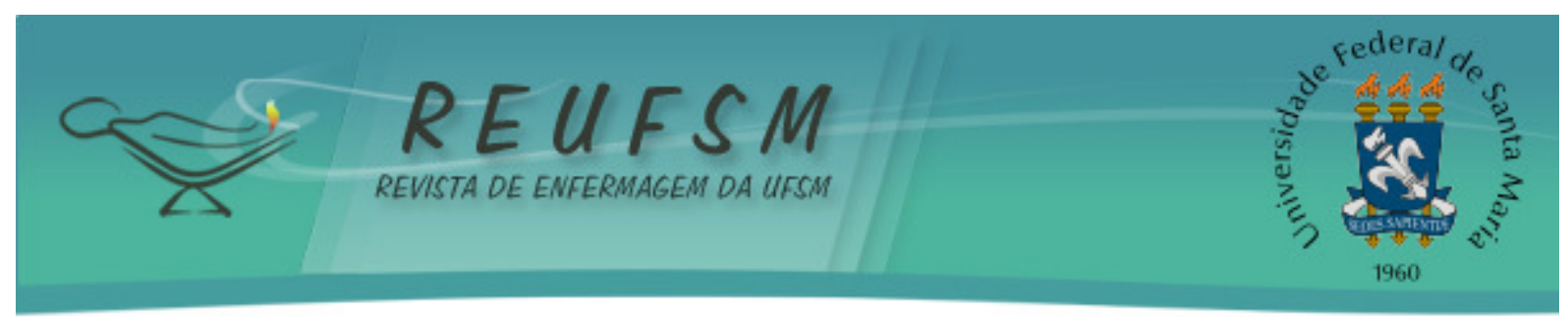

Essa proposta de cuidado dialogada entre profissional e usuário, oportuniza que este se torne ator do seu próprio cuidado, visto que seu conhecimento além de ser valorizado, será utilizado ao seu favor. Entretanto, para que isso ocorra de forma efetiva, o enfermeiro necessita de embasamento científico consistente para articular sobre a vasta diversidade de plantas medicinais que são utilizadas. Com isso, o presente trabalho tem a relevância de trazer informações de estudos científicos sobre plantas utilizadas pela população para distúrbios urinários. Nesse contexto, apresenta-se a questão norteadora da pesquisa: Quais as plantas medicinais indicadas por descendentes da zona rural, que podem ser utilizadas de forma a complementar o tratamento de distúrbios urinários?

Este artigo tem o objetivo investigar as plantas medicinais indicadas para distúrbios urinários, por descendentes da zona rural de um município da região Sul do Rio Grande do Sul.

\section{MÉTODO}

Consiste em um estudo de abordagem qualitativa, vinculada ao projeto "Plantas bioativas de uso humano por famílias de agricultores de base ecológica na região Sul do RS", desenvolvido pelo Laboratório de Cuidado à Saúde e Plantas Bioativas da Faculdade de Enfermagem da Universidade Federal de Pelotas e pela Embrapa Clima Temperado. A pesquisa foi financiada pelo Conselho Nacional de Desenvolvimento Científico e Tecnológico (CNPq).

0 critério para seleção dos participantes foi serem provenientes da zona rural, pois assim, provavelmente, teriam um conhecimento maior sobre o uso das plantas medicinais no cuidado à saúde, a qual este ambiente possibilita maior contato e diversidade de plantas.

A população estudada foi composta por nove participantes, os quais eram provenientes da zona rural do município do Capão do Leão/RS. A seleção dos participantes ocorreu por meio da secretária de saúde do município, a qual indicou um grupo de idosos como conhecedores de plantas medicinais.

Este grupo é composto por aproximadamente 30 idosos, na faixa etária de 60 a 80 anos, que se reúnem duas vezes por mês para a realização de oficinas de artesanato, plantas medicinais, culinária, dentre outras, buscando dessa maneira trocarem experiências.

Posterior ao contato com o grupo, realizado por meio da participação das pesquisadoras em uma reunião, foram indicados pelos integrantes, às pessoas conhecedoras sobre plantas medicinais.

Posteriormente a esse encontro, foram agendadas entrevistas com os três participantes indicados pelo grupo, utilizando-se após isso a técnica de coleta de dados snowball sampling. ${ }^{12}$ Esta técnica é baseada em uma amostragem não probabilística que define uma cadeia de informantes, isto é, ao identificar respondentes para a pesquisa, estes indicam outros respondentes e assim sucessivamente até que a suficiência amostral seja atingida. ${ }^{12}$

Foram utilizadas como instrumentos a entrevista semiestruturada e a observação simples, com registro fotográfico das plantas medicinais. As plantas coletadas e fotografadas foram identificadas por um botânico, vinculado à Embrapa Clima Temperado. As informações foram coletadas no período de julho a agosto de 2010.

$\mathrm{Na}$ entrevista foi abordado sobre o perfil dos participantes e o conhecimento destes sobre as plantas medicinais utilizadas para distúrbios urinários (indicação), além de informações sobre como adquiriram conhecimento referente ao tema. As plantas indicadas pelos participantes foram organizadas em uma tabela com nome científico, família, nome popular e uso mencionado.

Nesse sentido, a partir das informações dos participantes da pesquisa, foram pesquisados no SciELO (Scientific Electronic Library Online), PubMed (Public Medline), na LILACS (Literatura Latino-Americana em Ciências da Saúde), Science Direct e em alguns 


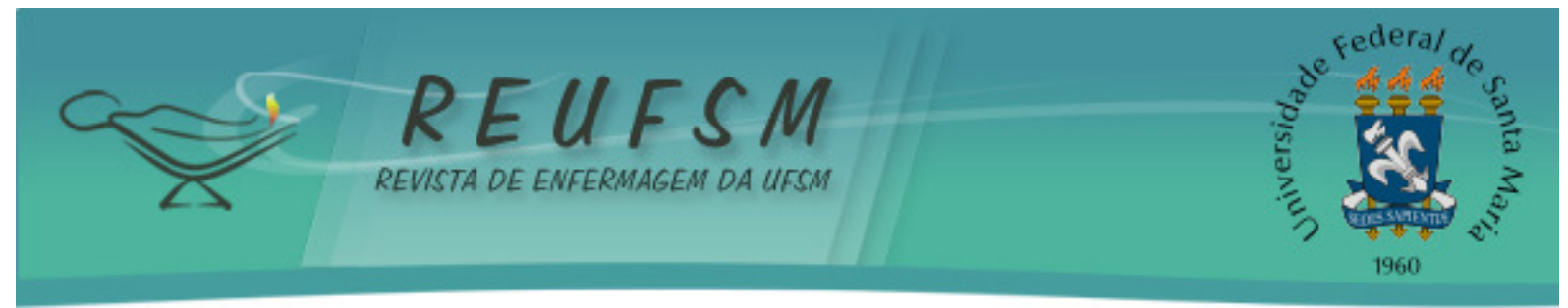

livros técnicos, estudos das plantas medicinais com efeitos antimicrobianos, antiinflamatórios e analgésicos, podendo estas plantas auxiliarem nas respectivas doenças.

Optou-se por realizar buscas dessas propriedades, pois se são práticas que complementam o tratamento alopático, uma planta com potencial anti-inflamatório e/ou analgésico poderá complementar o tratamento no alívio da dor. Destaca-se que as buscas foram realizadas pelo nome científico de cada planta medicinal citada.

0 projeto respeitou as normas de pesquisa envolvendo seres humanos, conforme a Resolução $196 / 96^{13}$ e recebeu aprovação do Comitê de Ética e Pesquisa da Faculdade de Medicina da Universidade Federal de Pelotas (072/2007).

\section{RESULTADOS}

A população estudada constitui-se de nove participantes, sendo sete do sexo feminino. A faixa etária oscilou entre 59 e 76 anos. Entre os entrevistados, sete possuíam o ensino fundamental incompleto, um o ensino fundamental completo e um o ensino médio completo. 0 levantamento etnobotânico evidenciou que sete plantas foram indicadas pelos participantes para problemas urinários, as quais estão apresentadas na Tabela 1.

Tabela 1- Plantas medicinais indicadas pelos participantes para distúrbios do trato urinário. Pelotas, Rio Grande do Sul, Brasil, 2012.

\begin{tabular}{cccc}
\hline Nome científico & Família & Nome popular & $\begin{array}{c}\text { Uso mencionado pelos } \\
\text { entrevistados }\end{array}$ \\
\hline Bauhinia sp. & Fabaceae & Pata-de-vaca & Infecção urinária \\
Bidens alba & Asteraceae & Picão-branco & Infecção urinária \\
Equisentum hyemale & Equisetaceae & $\begin{array}{c}\text { Cavalinha ou } \\
\text { Cola-de-lagarto }\end{array}$ & $\begin{array}{c}\text { Infecção de urina desmancha } \\
\text { pedra no rim. }\end{array}$
\end{tabular}

Fragaria vesca $\quad$ Rosaceae Morango Desmancha pedra no rim.

$\begin{array}{lc}\text { Petroselium crispum } \quad \text { Salsa } & \begin{array}{c}\text { Cistite; faz urinar; para } \\ \text { problemas dos rins. }\end{array}\end{array}$

$\begin{array}{llrl}\text { Phyllanthus sp. } \quad \text { Phyllanthaceae } & \begin{array}{c}\text { Erva-da-pedra, } \\ \text { Quebra-pedra, } \\ \text { Erva-pombinha }\end{array} & \begin{array}{c}\text { Para desmanchar pedra no rim; } \\ \text { elimina dores musculares, pois }\end{array} \\ & \text { elimina os cristas. }\end{array}$

Plantago australis Plantaginaceae Tansagem Infecção de urina

Fonte: Projeto "Plantas bioativas de uso humano por famílias de agricultores de base ecológica na região Sul do RS", 2010.

\section{DISCUSSÃO}

As infecções do trato urinário são causadas principalmente pela Escherichia coli (E. coli) entre $70 \%$ e $85 \%$ dos $\operatorname{casos}^{14}$, logo se evidencia que a maioria destas tem origem bacteriana. ${ }^{15}$ Para o tratamento, o preconizado é a utilização de antibacteriano que age no trato urinário com mínimos efeitos sobre as floras fecal e vaginal, diminuindo dessa forma, a incidência de infecções vaginais por leveduras. ${ }^{11}$ 


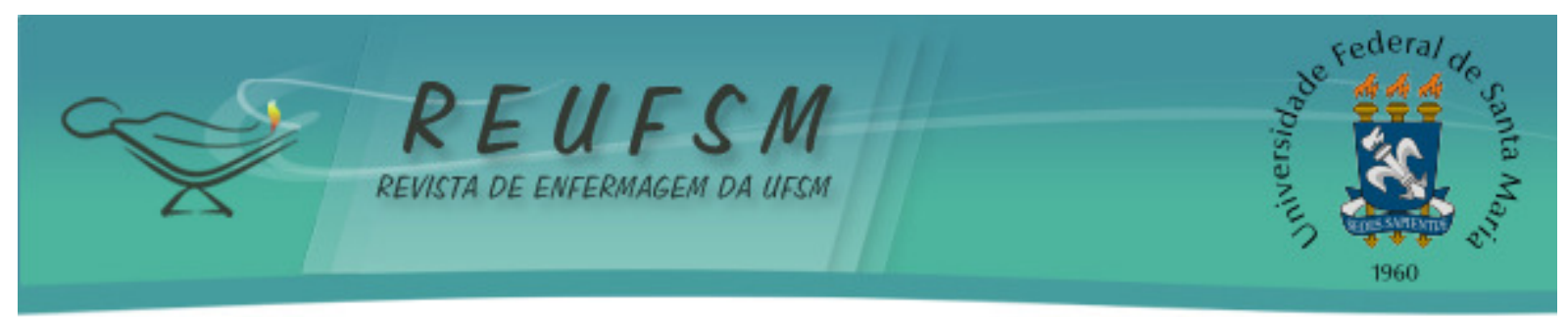

No entanto, não é toda a população que têm acesso às medicações alopáticas e muitas vezes, em determinados locais no Brasil o único recurso disponível são as plantas medicinais ${ }^{16}$ que podem atuar como uma prática complementar para determinadas doenças do trato urinário.

A inserção do uso das plantas medicinais no SUS ocorreu a partir da aprovação da PNPMF pelo Ministério da Saúde, em 2006. A partir desta política, surgiram outras publicações, como a Resolução da Diretoria Colegiada (RDC) $n^{\circ} 10$, publicada pela Agência Nacional de Vigilância Sanitária (ANVISA) em 2010, a qual descreve uma lista com notificação de 66 drogas vegetais. ${ }^{17}$

A RDC $10 / 10$ objetiva inserir com segurança, eficácia e qualidade, as plantas medicinais, fitoterápicos e serviços correspondentes a estes, no SUS. As plantas relacionadas são produtos de venda isentos de prescrição médica, destinados ao consumidor final. A efetividade destas plantas encontra-se amparada no uso tradicional e na revisão de dados disponíveis em literatura relacionada ao tema. ${ }^{17}$

Plantas medicinais, citadas para litíase renal podem ser utilizadas na prevenção da doença, pois segundo as informações dos participantes, "desmancham" os cálculos renais. Portanto um usuário que tem conhecimento da possível tendência de desenvolver esse problema poderá ingerir os chás de plantas que cientificamente comprovam o auxílio na eliminação de cálculos renais.

Foi indicada pelos participantes, a planta Phyllanthus sp. para a doença supracitada, que nessa pesquisa foi possível identificar apenas o gênero, contudo realizando buscas na literatura científica, a RDC 10/10 informa que o Phyllanthus niruri possui indicações para litíase renal, por auxiliar na eliminação de cálculos renais pequenos. ${ }^{17} \mathrm{~A}$ eliminação destes cálculos, provavelmente diminuirá as dores que são resultados da doença, vindo ao encontro das informações dos participantes.

Um estudo realizado no México mostrou que o extrato de Equisentum hyemale possui ação antimicrobiana, com resposta específica moderada contra o Staphylococcus aureus. ${ }^{18^{\prime}} \mathrm{Na}$ RDC $10 / 10$ cita a Equisetum arvense para edemas por retenção de líquidos. ${ }^{17}$

Como indicado pelos participantes deste estudo, esta planta é utilizada para edemas, eliminando a retenção de líquido, logo pode auxiliar na eliminação de cálculos renais. Diante dessa informação, é possivel perceber a importância de uma visão sistêmica no cuidado ao usuário, exigindo que os profissionais coloquem esta percepção em prática.

Entretanto, no processo de trabalho dos profissionais da saúde, percebem-se dificuldades em prestar um cuidado integral. Isto pode estar relacionado ao fato da formação ainda ser focada no modelo biomédico, repercutindo em insatisfação da população em relação ao sistema de saúde.

O extrato da Fragaria vesca, obtido das raízes, possui substâncias chamadas procianidinas que tem atividade antibacteriana ${ }^{19}$, auxiliando no efeito antimicrobiano, mas necessariamente não na eliminação de cálculos renais.

A despeito de essas plantas serem utilizadas de maneira a complementar o tratamento alopático, é importante que a enfermagem e demais profissionais explanem aos usuários sobre os cuidados no uso, objetivando promover à saúde.

Os cálculos renais geralmente são formados no trato urinário, quando as concentrações urinárias de determinadas substâncias, tais como: oxalato de cálcio, fosfato de cálcio e ácido úrico estão aumentadas. ${ }^{11}$ Diante disso, orientações como o aumento da ingesta de líquidos, em que o usuário deve procurar beber de oito a dez copos de água diariamente, para assim manter a urina diluída, evitando a formação do cálculo. ${ }^{11}$

A educação em saúde realizada pelos profissionais de saúde é importante, pois é alto o risco de recidiva dos distúrbios urinários, como as infecções urinárias e urolitíase. ${ }^{11} A$ enfermeira, além de estimular a ingestão hídrica, quando esta não é contraindicada, também pode orientar 


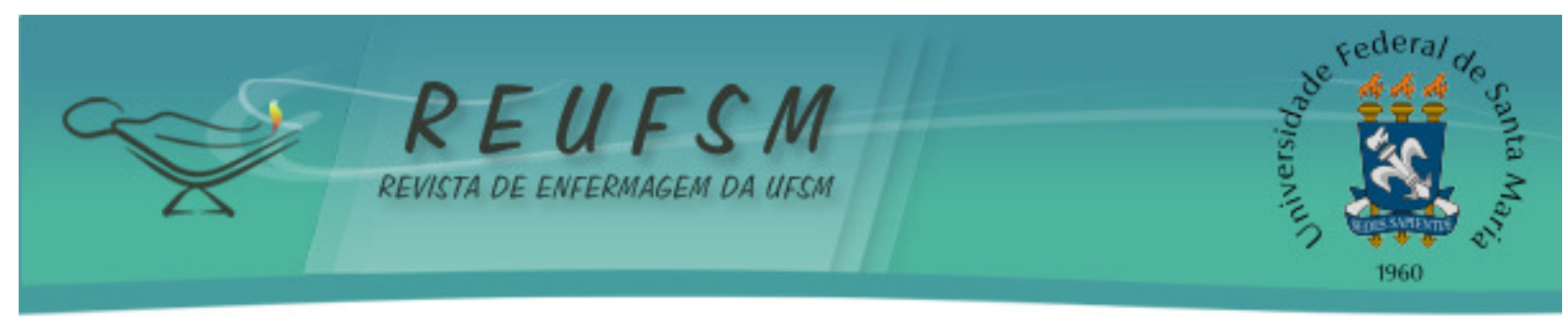

sobre a importância da deambulação, pois a imobilização prolongada lentifica a drenagem renal, alterando o metabolismo do cálcio e favorecendo a formação do cálculo. ${ }^{10-11}$

Os cálculos renais, dependendo do tamanho, bloqueiam o fluxo da urina, desenvolvendo obstrução e, muitas vezes, a urina acaba ficando estagnada, favorecendo assim um meio propício para infecção urinária. ${ }^{11}$

Diante disso, algumas plantas foram indicadas pelos participantes desse estudo para infecções do trato urinário, as quais fazem parte dos distúrbios urinários. A espécie Bidens alba possui características e propriedades semelhantes que a Bidens pilosa. ${ }^{20}$ Não foram encontradas pesquisas relacionadas ao $B$. alba, mas para o $B$. pilosa, um estudo ${ }^{17}$ mostrou que os extratos apresentaram maior atividade contra Bacillus cereus e $E$. coli quando comparado ao sulfato de gentamicina. ${ }^{21} \mathrm{Na}$ RDC $10 / 10$ esta planta também é citada, porém não para infecções do trato urinário e sim para icterícia.

Pesquisas como essas, que comparam o efeito de plantas com medicamentos alopáticos, demonstram a preocupação dos pesquisadores em encontrar novas opções antimicrobianas devido à resistência dos microrganismos patogênicos a diversas drogas.

Ressalta-se que os resultados encontrados em uma pesquisa sobre B. pilosa ${ }^{21}$, demonstraram que a planta obteve maior efeito do que o antibiótico testado, evidenciando assim, a riqueza da flora e a importância da sua valorização.

Extratos metanóicos de Plantago lanceolata apresentaram boa atividade contra o gênero Candida spp. ${ }^{22} \mathrm{Na}$ RDC $10 / 10$ consta que a Plantago major tem indicação para inflamações da boca e faringe. ${ }^{17}$

Para Petroselium crispum foi encontrado que esta planta possui efeito analgésico, logo auxiliando no tratamento da infecção urinária por propiciar alívio da algia. ${ }^{20}$

Destacamos que a planta medicinal, apesar de causar menos efeitos colaterais, quando comparada à medicação alopática, também pode causar interações com outras substâncias e muitas devem ser utilizadas com cautela, diante de determinadas doenças.

Os profissionais de saúde precisam estar atentos ao usuário, buscando realizar uma anamnese completa, pois muitas vezes estes possuem além da litíase renal ou infecção urinária, outras doenças associadas, exigindo um cuidado maior na indicação de plantas medicinais.

As infecções urinárias e a litíase renal são doenças que podem ser prevenidas. A prevenção das doenças e a realização de ações de promoção à saúde, como a educação popular $^{23}$, não são tarefas fáceis em uma sociedade, que geralmente busca a cura imediata da doença. Esta demanda é um desafio para os profissionais.

Neste contexto, o enfermeiro deve procurar compreender a complexidade do processo saúde/doença no seu processo de trabalho, buscando promover a saúde do indivíduo, a formação do vínculo e estimulando o autocuidado. ${ }^{24}$

Diante desse resultado, percebe-se a riqueza do conhecimento popular, o qual pode ser integrado no cuidado prestado, agregando o saber do uso das plantas medicinais nas práticas realizadas pelos profissionais.

É necessário formar profissionais que saibam escutar e valorizar o conhecimento popular, permitindo que o usuário seja sujeito ativo na elaboração do plano de cuidado a ser realizado, evitando a reprodução acrítica do modelo biomédico.

\section{CONSIDERAÇÕES FINAIS}

Esta pesquisa que investigou o saber popular referentes às plantas medicinais utilizadas para distúrbios urinários, demonstrou que sete plantas são as mais utilizadas, sendo estas: Bauhinia sp., Bidens alba, Equisetum hyemale, Fragaria vesca, Petroselium crispum, Phyllanthus sp. e Plantago australis.

Comprovou-se por meio de estudos científicos que todas as plantas medicinais 


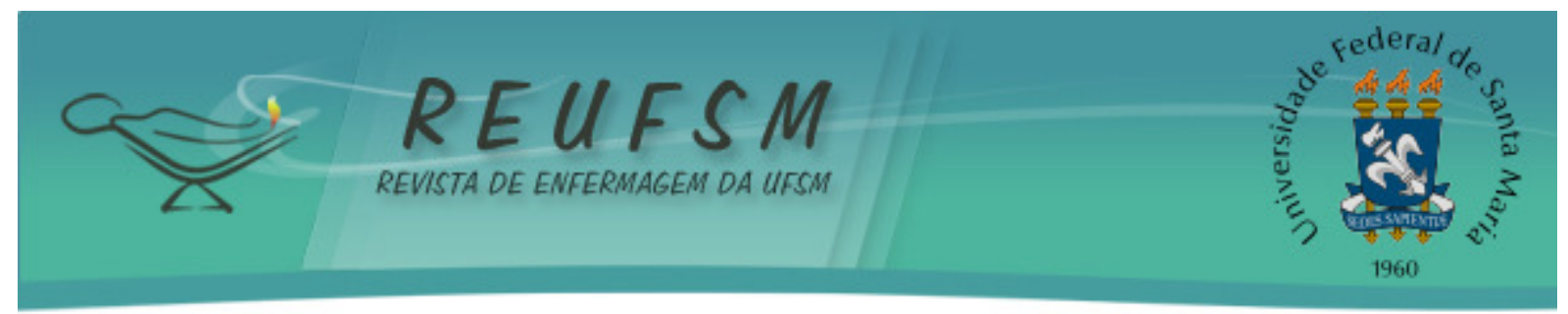

indicadas pelos participantes vêm ao encontro da literatura científica, mostrando, com isso, a riqueza deste saber popular.

Nesse sentido, é preciso que os profissionais busquem conhecer o assunto para que, desta maneira, possam orientar corretamente os usuários, como também estimular a promoção da saúde em relação aos distúrbios urinários. Além disso, alertar a população sobre as possíveis interações medicamentosas que podem resultar da utilização inadequada de uma planta.

\section{REFERÊNCIAS}

1. World Health Organization (WHO). Regional office for the Western Pacific. Research guidelines for evaluating the safety and efficacy of herbal medicines. Manila: WHO; 1993.

2. World Health Organization (WHO). The world medicines situation 2011: traditional medicines: global situation, issues and challenges. Geneva: WHO; 2011.

3. Dutra MG. Plantas medicinais, fitoterápicos e saúde pública: Um diagnóstico situacional em Anápolis, Goiás [dissertação]. Anápolis: Centro Universitário de Anápolis UniEvangélica; 2009. 112 p.

4. Silva SP. Estratégias de implantação do Programa Nacional de Plantas Medicinais e Fitoterápicos na rede municipal de saúde de Pindamonhangaba- SP [Internet]. In: IX Jornada Paulista de Plantas Medicinais; 2009 set 22-24; São Paulo. São Paulo: Infobibos; 2009 set [acesso em 2012 set 5]. Disponível em: http://www.infobibos.com/Artigos/2009_4/estrategias/index.htm.

5. Souza ADZ, Mendieta MC, Hohenberger GF, Silva MM, Ceolin T, Heck RM. Menstrual cramps: a new therapeutic alternative care through medicinal plants. Health [Internet]. 2013 Jun [acesso em 2013 jul 3];5(7):1106-09. Disponível em: http: / /www.scirp.org/Journal/Home.aspx?JournalID=65\&utm_campaign=aimScope\&utm_s ource=e_cp\&utm_medium=e_cp_health_20130812 doi: 10.4236/health.2013.57149.

6. Ministério da Saúde (BR). Política Nacional de Práticas Integrativas e Complementares no SUS - PNPIC-SUS. Brasília (DF): Ministério da Saúde; 2006.

7. Ministério da Saúde (BR). Decreto no 5.813, de 22 de junho de 2006. Aprova a Política Nacional de Plantas Medicinais e Fitoterápicos e dá outras providências. Diário Oficial da União, Brasília; 2006 jun 23. Seção 1, no 119.

8. Ministério da Saúde (BR). Cadernos de Atenção Básica. Práticas Integrativas e Complementares: plantas medicinais e fitoterapia na Atenção Básica [Internet]. Brasília (DF): Ministério da Saúde; 2012 [acesso em 2012 set 5]. Disponível em: http://189.28.128.100/dab/docs/publicacoes/geral/miolo_CAP_31.pdf.

9. Pereira RS, Sumita TC, Furlan MR, Jorge AO, Ueno M. Atividade antibacteriana de óleos essenciais em cepas isoladas de infecção urinária. Rev Saude Pública. 2004;38(2):326-8.

10. Souza ADZ, Heck RM, Ceolin T, Borges AM, Ceolin S, Lopes ACP. O cuidado com plantas medicinais para às infecções do trato urinário: um desafio a enfermagem. Rev Pesq Cuid Fundam online [Internet]. $2012 \mathrm{abr} /$ jun [acesso em 2012 jul 5];4(2):2367-76. Disponível em: http://dialnet.unirioja.es/servlet/ejemplar?codigo=307601.

11. Smeltzer SC, Bare BG, Hinkle JL, Cheever KH. Brunner \& Suddarth - Tratado de enfermagem médico cirúrgica. 11ㅇe ed. Rio de Janeiro: Guanabara; 2009.

12. Goodman LA. Snowball Sampling. Annals of Mathematical Statistics. ISEC-ETSIAM, Universidad de Cordoba. 1999;32(1):148-70. 


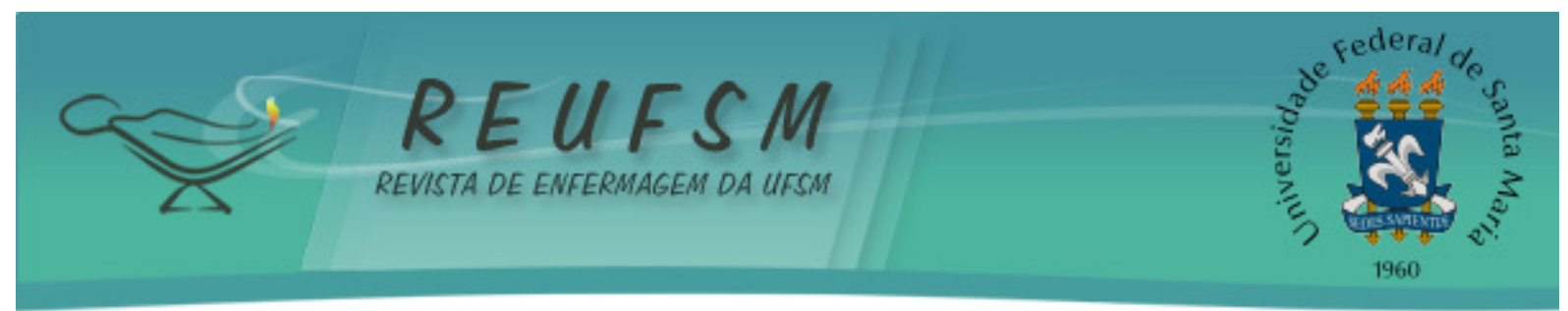

13. Ministério da Saúde (BR). Conselho Nacional de Saúde. Resolução 196, de 10 de outubro de 1996: diretrizes e normas regulamentadoras de pesquisa envolvendo seres humanos. Brasília: Ministério da Saúde; 1996.

14. Gupta K, Hooton TM, Stamm WE. Increasing antimicrobial resistance and the management of uncomplicated community-acquired urinary tract infections. Ann Intern Med. 2001;135:41-50.

15. Ministério da Saúde (BR). Agência Nacional de Vigilância Sanitária. Manual de Microbiologia Clínica para Controle de Infecções em Serviços de Saúde. Brasília: Ministério da Saúde; 2004.

16. Di Stasi LC. Plantas medicinais verdades e mentiras: o que os usuários e os profissionais de saúde precisam saber. 1a ed. São Paulo: UNESP; 2007.133 p.

17. Ministério da Saúde (BR). Agência Nacional da Vigilância Sanitária. Notificação de drogas vegetais. Resolução RDC № 10, de 09 de março de 2010 [internet]. Brasília: ANVISA; 2010. 2010 mar [acesso em 2013 jun 9]. Disponível em: http://www.brasilsus.com.br/legislacoes/rdc/103202-10.

18. Navarro V. Antimicrobial evaluation of some plants used in Mexican traditional medicine for the treatment of infectious diseases. J Ethnopharmacol. 1996;53:143-7.

19. Vennat B, Pourrat A, Pourrat H, Gross D, Bastide P, Bastide J. Procyanidins from the roots of Fragaria vesca: characterization and pharmacological approach. Chem Pharm Bull. 1988;36(2):828-33.

20. Lorenzi $\mathrm{H}$, Matos FJA. Plantas Medicinais no Brasil: nativas e exóticas. 2a ed. Nova Odessa, SP: Instituto Plantarum; 2008. 544 p.

21. Rojas JJ, Ochoa VJ, Ocampo SA, Muñoz JF. Screening for antimicrobial activity of ten medicinal plants used in Colombian folkloric medicine: a possible alternative in the treatment of non-nosocomial infections. BMC Complement Altern Med. 2006;6(2):1-6.

22. Yigit $D$, Yigit $N$, Ozgen $U$. An investigation on the anticandidal activity of some traditional medicinal plants in Turkey. Mycoses 2009;52(2):135-40.

23. Jahn AC, Guzzo PC, Costa MC, Silva EB, Guth EJ, Lima SBS. Educação popular em saúde: metodologia potencializadora das ações do enfermeiro. Rev Enferm UFSM [Internet]. 2012 set/dez [acesso em 2013 jul 11];2(3):547-52. Disponível em: http://dx.doi.org/10.5902/217976923522.

24. Wosnes KR, Locatelli K, Noguez PT, Ceolin, T. O conhecimento dos diabéticos sobre o cuidado com os pés. Enfermería Comunitaria [Internet]. 2010 [acesso em 2013 jun 15];6(2). Disponível em: http://www.index-f.com/comunitaria/v6n2/ec7485.php.

Data de recebimento: 08/08/2013

Data de aceite: 03/02/2014

Contato com autor responsável: Andrieli Daiane Zdanski de Souza

Endereço postal: Rua Roque Calage $n^{\circ}$ 240, Bloco: B; Apto: 306. Bairro: Passo da Areia.

Cep: $91350-090$ Porto Alegre, RS, Brasil.

E-mail: andriele_zdanski@hotmail.com 